\title{
PRESIDENTIAL POPULARITY AND REPUTATION
}

BY

\author{
O.H. SWANK*
}

\section{INTRODUCTION AND SUMMARY}

Recent economic studies on government behaviour often assume that governments aim to stay in power. In such studies, the relationship between the popularity of the incumbent U.S. President (or party) and economic variables is obviously a very important one. Since the first studies on vote and popularity functions appeared, estimations of these functions have been based on the hypothesis that voters hold the incumbent President responsible for economic outcomes. Evidence on voting behaviour has only provided weak support for this hypothesis. Different studies have found different economic variables influencing the popularity of a President. Moreover, the popularity and vote functions appeared to be very unstable. Nevertheless, this hypothesis has acquired an established position in studies on government behaviour.

In the present paper a new hypothesis on voting behaviour is formulated and tested for the United States. Following most previous studies, voters are assumed to be ignorant about the working of the economy. Voters do, however, perceive ideological differences between political parties. From these assumptions, the alternative hypothesis can be derived that the popularity of a President (or party) depends on the problems a country faces. According to this hypothesis, a President does not necessarily benefit from favourable economic outcomes. Instead, he benefits from economic problems if voters believe he can handle them better than his opponents. A comparison of the estimates of the conventional and alternative hypothesis turns out in favour of the alternative one.

This paper is organized as follows. It starts with a short review of the literature on popularity and vote functions. It appears that in existing studies, a plausible explanation of how voters' expectations regarding the performance of Presidential candidates are formed has been lacking. In section 3 , we try to gain a clear understanding of voters' expectations by posing the question:

* Tinbergen Institute and Macro-economic Policy Group, Erasmus University Rotterdam. I am indebted to J.C. Siebrand, A.S. Brandsma, G.E. Hebbink, N. van der Windt and an anonymous referee for many useful suggestions. 
'What do voters know about the economic policy problem?' In answering this question we use Theil's formulation of the economic policy problem. In this section an alternative hypothesis is formulated, viz. that the popularity of a President depends on the problems a country faces. In section 4, this hypothesis and the conventional hypothesis are tested for the United States for the postwar period. It appears that the data do not support the old hypothesis at all, but that they provide strong support for the alternative hypothesis. The acceptance of the alternative hypothesis has important implications for existing studies on government behaviour. Section 5 describes some promising directions for further research. Section 6 , finally, concludes this paper.

\section{A SHORT REVIEW}

Following Mueller (1970), Goodhart and Bhansali (1970) and Kramer (1971), numerous studies have examined the relationship between the performance of administrations and their popularity. The studies in this field are generally empirically oriented, trying to give support to the hypothesis that voters hold the incumbent party (or President) responsible for economic developments. In what follows this hypothesis will be referred to as the 'score hypothesis.' Usually, the equations derived from the score hypothesis have the following form (Paldam, 1981)

$$
\begin{array}{r}
p o p_{t}=f\left(g_{t}^{1} \ldots \ldots \ldots g_{t-k}^{1}, \ldots, g_{t}^{n} \ldots \ldots . g_{t-k}^{n},\right. \\
\left.p_{t}^{1} \ldots \ldots \ldots p_{t-m}^{1}, \ldots, p_{t}^{n} \ldots \ldots \ldots p_{t-m}^{n}\right)
\end{array}
$$

where $p o p$ is a popularity index, $g^{1}$ to $g^{n}$ are economic explanatory variables and $p^{1}$ to $p^{n}$ are political explanatory variables.

On the basis of the popularity index we can distinguish two types of functions, viz. the vote and the popularity functions. The former explains election results and the latter explains the popularity of a President as measured by polls. There are some obvious differences between vote and popularity functions. Later, in discussing the empirical results we will return to these differences. For the moment, we primarily focus on popularity functions.

Unemployment, inflation and disposable income are frequently used as variables representing economic conditions $\left(g^{i}\right)$. Rising unemployment and inflation are supposed to diminish the popularity of a President while a growing disposable income is supposed to augment the popularity of a President. No clarity exists on the proper specification of these variables. Questions such as 'Is the popularity of a President affected by the level of unemployment or by its change?' are still unanswered.

Factors affecting the popularity of a President that are not related to economic conditions are called political factors $\left(p^{i}\right)$. Since these factors are often hard to quantify, they are usually represented by dummy variables. Various 
political variables have appeared in previous studies on popularity functions. Dummy variables are often introduced to represent the personality of a President (Goodhart and Bhansali, 1970; Mueller, 1970; Frey and Schneider, 1978a and 1978b; Hibbs, 1982; Chappell, 1983). In popularity functions for the United States a dummy for the Watergate scandal is sometimes included (Frey and Schneider, 1978a and 1978b; Hibbs, 1982). Other political factors often appearing are a 'rally round the flag' variable reflecting the observation that the popularity of a President increases during international crises (Mueller, 1970; Hibbs, 1982) and a 'honeymoon' variable which indicates that the popularity of a President usually increases just after his election (Frey and Schneider, 1978; Mosley, 1984).

Most estimates of popularity and vote functions lend support to the hypothesis that the popularity of a President is related to economic conditions ( $c f$. Paldam, 1981; Van Winden, 1983). Unfortunately, the various results do not speak in one voice. For the United States, inflation is the only variable which is generally found to influence the popularity of a President significantly. On the contrary, unemployment and disposable income are sometimes found not to be related to the popularity index. Moreover, some studies suggest that popularity functions are rather unstable ( $c f$. Paldam, 1981; Van Winden, 1983; Mosley, 1984). By cutting the estimation period into slices it can be shown that in some periods the economic variables usually considered have no significant influence on the popularity of a President or even have coefficients with an unexpected sign.

In the pioneering studies on vote and popularity functions a theoretical framework has been lacking. The equations to be estimated have been based on some general empirical notions. Fair (1978) first tried to develop a voter'schoice model. The idea behind his model is quite simple. Voters are assumed to maximise their expected utility, which depends on the expected performance of the incumbent President and a loyalty term specific to each voter. The loyalty term in Fair's model represents the loyalty of a voter to the incumbent party or the President. Fair assumes that the differences of loyalty to parties are evenly distributed across voters. In Fair's model voters' expectations on the performance of Presidents are formed rather primitively. The present and past values of a few economic indicators serve as a proxy for the expected performance of a President.

This view on the voter has been criticized in two ways. First, some authors even view a voter as less sophisticated, regarding voters as being ignorant about economic issues ( $c f$. Edwards, 1983; Mosley, 1984). According to these authors it is important to realize that voters receive their information on economic issues from papers and magazines. This information is very limited since these media only pay attention to economic crises. Hence, it is concluded that voters only react on economic variables if they are above their crisis levels. This line of arguing seems to provide a reasonable explanation for the instability of vote and popularity functions. Second, Chappell (1983) and MacRae (1977 and 
1981) assume a more sophisticated voter than Fair. They assume a strategic voter who maximises his utility, taking into account the future consequences of past and present policies. Chappell has found that the 'sophisticated voter hypothesis' does a better job of explaining the popularity of a President than the 'naive voter hypothesis.' MacRae's results are in line with Chappell's findings.

The previous paragraphs show that both a model with a less sophisticated voter and a model with a more sophisticated voter improve Fair's model. From the existing empirical results, it is apparently hard to detect how voters' expectations are actually formed.

Borooah and Van der Ploeg (1983) have adopted Fair's model but they assume that the loyalty term is logistically distributed. The shape of the logistic distribution is in accordance with the conventional view that a political party has strong supporters having a high loyalty to their party and weak supporters having a low loyalty to their party. In fact, the weak supporters of all parties can be regarded as the floating voters, who are supposed to react upon changing economic conditions (see also Hanushek and Jackson, 1977 and Van Winden, 1983). The logit model has the additional advantage that it enables us to analyse multi-party systems (see also Renaud and Van Winden, 1987).

The theoretical underpinning of the vote and popularity function has not led to quite different empirical results. The equations estimated by e.g. Borooah and Van der Ploeg (1983) are in principle equal to those of Kramer (1971). However, the choice model sharpens our intuition. It facilitates detecting the main pitfalls of the vote and popularity functions.

From the discussion above two conclusions can be drawn. First, a plausible explanation of how voters' expectations are formed regarding the performance of parties or Presidents is still lacking. Second, most estimates of popularity and vote functions suggest that such functions are rather unstable.

\section{VOTERS' EXPECTATIONS}

As we have seen in the previous section, in modelling voting behaviour the crucial problem is the determination of voters' expectations regarding the performance of a President. A question closely connected with this problem is 'What do voters know about the economic policy problem?' In order to provide a clear picture of the possible answers to this question and to facilitate the judgment of the plausibility of these answers, the traditional formulation of the economic policy problem is a convenient starting point.

Theil (1958) has formulated the problem of economic policy as minimising a quadratic cost function subject to restrictions reflecting the perceived working of the economy. The cost function comprises target and instrument variables in deviation from their desired values. The variables frequently used in vote and popularity functions often appear in cost functions. We can for- 
malize the economic policy problem with two target variables as follows:

$$
\begin{aligned}
& \text { minimise (x) } C=\alpha_{1}(u-u d)^{2}+\left(1-\alpha_{1}\right) p^{2}+\alpha_{2} \mathbf{x}^{2} \\
& \text { subject to } \quad u, p=f(\mathbf{x}, \mathbf{s}) \\
& \text { yields } \quad \mathbf{x}=g\left(\alpha_{i}, u d, \mathbf{s}\right) \text { and } u, p=h\left(f(\cdot), \alpha_{i}, u d, \mathbf{s}\right)
\end{aligned}
$$

where the coefficients $\alpha_{i}$ represent the preference scheme of the policy-makers, $u$ is the unemployment rate, $u d$ is the ideal value of the unemployment rate, $p$ is the inflation, $\mathbf{x}$ is a vector of instrument variables and $\mathbf{s}$ is a vector of noncontrollable variables. Solving the economic policy problem shows that the economic outcomes $u$ and $p$ depend on the preference scheme of the policymakers, the ideal values of all variables, the values of non-controllable variables and, of course, the working of the economy, $f(\cdot){ }^{1}$

Let us now use this framework to describe the way voter's expectations regarding the performance of a President are determined. As appeared from the previous section, in pioneering studies on voting behaviour voters base their choices on present values of $u$ and $p$, neglecting the factors which have led to these values. The policy framework suggests that the values of $u$ and $p$ provide a poor indication for their future values since they ignore the influence of non-controllable variables, the preference scheme of the policy makers and the working of the economy. As we have discussed, Chappell (1983) and MacRae (1977 and 1981) have assumed a more sophisticated voter, being aware of the short-run and long-run trade-offs between economic target variables. In terms of the economic policy framework, the voter is assumed to know the working of the economy (equation 3). Hence, in judging the expected performance of a President the voter is assumed to be able to consider the future consequences of past and present policies. Voters' expectations regarding $u$ and $p$ are still a bit naive, since future policies are not taken into consideration. As far as we know, there are no studies published yet which assume that voters have different perceptions about the preference schemes of Presidents.

The assumption that voters are naive may run counter to the intuition of economists who generally assume individual rationality (Chappell, 1983). However, the naive voter hypothesis is not necessarily in contradiction with the rational voter hypothesis. To illustrate this we reconsider the voter's-choice model. The voter's-choice model is based on the assumption that voters maximise their utility through their votes. In a two-party system a voter elects for President $D$ if his expected utility under President $D$ is higher than his expected

1 In fact, $f(\cdot)$ describes the perceived working of the economy, while economic outcomes depend on the actual working of the economy. As the economic policy framework only serves illustrative purposes in this paper we have ignored this complication. 
utility under President $R$

$$
\begin{aligned}
& E\left(V_{i}^{D}\right)>E\left(V_{i}^{R}\right) \quad \Rightarrow \quad \text { voter } i \text { elects President } D \\
& E\left(V_{i}^{R}\right)>E\left(V_{i}^{D}\right) \Rightarrow \text { voter } i \text { elects President } R,
\end{aligned}
$$

where $E\left(V_{i}^{j}\right)$ is voter $i$ 's expected utility under President $j$. If voter $i$ 's knowledge about economic policy is limited, his expectations about future outcomes may differ from the expectations he would have under complete knowledge. Hence a not fully informed voter risks voting for a President under whose administration his utility would be lower than under that of the President's opponent. We call this a 'wrong' vote. Furthermore, we assume that voters have the possibility to acquire knowledge of economic policy against certain costs (disutility). The voter's problem is now formulated as "how much knowledge to acquire to avoid a 'wrong' vote." The solution of this problem is quite obvious. In general, the influence of an individual vote is negligible since, in many democratic countries, the election outcomes depend on millions of votes. A voter's 'wrong' vote does not decrease his utility, since the election outcomes are not changed by it. So, a voter has no incentive to increase his knowledge of economic issues since the possible benefits derived from it never exceed the costs of acquiring knowledge. It emerges that the assumption that voters understand the structure of the economy (Chappell, 1983; MacRae 1877 and 1981 ) is rather implausible. Economists disagree about the working of the economic system. From this point of view we cannot expect that voters know all answers.

In previous studies on voting behaviour the main point of controversy has been voters' knowledge of the economic system. Theil's framework tells us that there is another aspect of the economic policy process on which voters might base their expectations regarding the performance of President candidates viz. the preference schemes of President candidates. In Theil's framework different preference schemes of President candidates would imply that the values of $\alpha_{i}$ depend on the President in office. In other words, the values of $\alpha_{i}$ indicate the President's ideological characteristics. If voters are assumed to have knowledge of the values of $\alpha_{i}$ they are considered to be able to perceive ideological differences between President candidates.

There is evidence in favour of the hypothesis that Presidents from different parties have different preference schemes. Hibbs (1977 and 1986) has shown that macro-economic outcomes can partly be explained by the political colour of the President in power. For the United States he has found that under a Democratic administration unemployment is about 2 percentage points lower than under a Republican administration. Beck (1982) has estimated a much weaker relationship; an impact of political party on unemployment of about 1 percent. Furthermore he has found that the relationship is rather unstable. We need not be surprised by this result. Theil's framework shows that the pref- 
erence scheme of a President is only one of the many variables affecting economic outcomes.

The basic idea behind the relationship between economic outcomes and the colour of a President is that the core members of the parties in the United States have some specific features with respect to their social backgrounds and interests. Strong supporters of the Democratic party often belong to the lower classes, which generally express a great fear about unemployment. On the other hand the core constituency of the Republican party consists of upper classes, holding a relatively large share of capital. These classes suffer more from inflation than from unemployment. The suggestion emerges that the parties in the United States have different priorities. The Democratic party assigns higher priority to fighting unemployment and the Republican party assigns higher priority to suppressing inflation. In Theil's framework we can formalize this as follows

$$
\alpha_{1}^{D} / 1-\alpha_{1}^{D}>\alpha_{1}^{R} / 1-\alpha_{1}^{R}
$$

where $\alpha_{1}^{i}$ represents the costs attached to deviations of the unemployment rate from its desired value by President $i$, and $1-\alpha_{1}^{i}$ is the costs attached to inflation by President $i$. For the economic outcomes (6) has important implications. It leads to the hypothesis that different parties perform better on different issues. In the proceeding this hypothesis will be referred to as the 'issue hypothesis.' Under the assumption that voters perceive equation 6 - and this assumption is quite plausible since (6) is based on voters' characteristics - voters' President choices depend on the economic problems a country faces. Note that this does not require that voters know the exact values of $\alpha_{i}$. For the United States the issue hypothesis means that the popularity of a Democratic (Republican) President is positively (negatively) related to unemployment and negatively (positively) related to inflation. In other words, in periods of high unemployment (inflation) the call for a Democratic (Republican) President will be greater.

The issue hypothesis sharply contrasts with the score hypothesis that voters hold the incumbent President responsible for economic outcomes. The score hypothesis has led to equations of the following form

$$
\text { pop } p_{t}=\beta_{0} u_{t}+\beta_{1} p_{t}+. . \quad \text { where } \beta_{0}<0 \text { and } \beta_{1}<0 \text {. }
$$

Equation 7 expresses that the popularity of the incumbent President is negatively related to unemployment and inflation, regardless of whether there is a Democratic or a Republican President in power. The issue hypothesis can be formalised as follows

$$
\operatorname{pop}_{t}=\beta_{0}\left(\operatorname{dem}_{t} u_{t}-\left(1-\operatorname{dem}_{t}\right) u_{t}\right)+\beta_{1}\left(\operatorname{dem}_{t} p_{t}-\left(1-\operatorname{dem}_{t}\right) p_{t}\right)+\ldots
$$

where dem is a dummy variable taking the value 1 when a Democratic President 
is in office and taking the value 0 when a Republican President is in office. In equation 8 the direction of the impact of unemployment and inflation on the popularity of the incumbent President depends on whether there is a Republican or a Democratic President in power. If voters believe that Democrats assign higher priority to reducing unemployment than Republicans we expect that $\beta_{0}>0$ and $\beta_{1}<0$.

\section{EMPIRICAL RESULTS}

In this section we present estimates of popularity functions for the United States for the post-war period (1955-1986). As dependent variable serve the answers to the well-known Gallup-poll question 'Do you approve or disapprove of the way [name of President] is handling his job as President?.' Following several studies on voting behaviour, we assume that the approval rates (pop) are logistically distributed:

$$
p o p_{t}=1 /\left(1+e^{-\mathbf{x}_{t} \boldsymbol{\beta}}\right),
$$

where $\mathbf{x}$ is a vector of independent variables and $\boldsymbol{\beta}$ is a vector of coefficients. The logit model can be written as

$$
L=\log (p o p /(1-p o p))=\mathbf{x}_{t} \boldsymbol{\beta}
$$

The logit model is heteroscedastic since the variance of the error term depends on $\mathbf{x}_{t}$. The equations in this section are therefore estimated with generalized least squares. All functions are estimated with annual data. ${ }^{2}$ This has the advantage that we get rid of short-run fluctuations in Presidential popularity resulting from, for example, good or bad performance of the President on television. On the other hand, by using annual data the number of degrees of freedom decreases. As a result, we cannot use many independent variables.

With regard to the political explanatory variables we have confined ourselves to the following variables. First, we introduce a dummy variable (EIS) to account for Eisenhower's unique personality. Among post-war Presidents Eisenhower took a unique position since his popularity was partly independent of his involvement in partisan politics (Edwards, 1983). Similar dummy variables are introduced for the periods in which Nixon and Reagan were in office (NIX resp. $R E A){ }^{3}$ Finally, we introduce a dummy variable to account for the impact of the Watergate scandal on Nixon's popularity. The dummy $(W A T)$ takes the value 1 over the period 1973-1974, and is 0 otherwise. The economic variables include unemployment $(u)$ and inflation $(p)$.

2 The approval rates are converted from monthly to annual using averaging.

3 We experimented with dummy variables for all Presidents and eliminated them from the equation if they took low $t$-values (in general $t$-values less than unity). 


\subsection{Testing the Score Hypothesis}

In order to test the score hypothesis we estimate

$$
L_{t}=\beta_{0} p_{t}+\beta_{1} u_{t}+\beta_{2} W A T+\beta_{3} E I S+\beta_{4} N I X+\beta_{5} R E A
$$

The estimation results are presented in the first column of Table 1 . The results do not give much support to the score hypothesis. Only the coefficient for inflation has the expected sign and is significant at a 5 percent level. The relationship between popularity and unemployment appears to be a positive one, which is clearly inconsistent with the score hypothesis. The coefficient for the Watergate dummy gets the expected sign, but is insignificant at conventional levels. We have experimented with slightly different specifications but found no specification supporting the score hypothesis. This is not really surprising. Several studies have found only weak and sometimes unexpected relations between popularity and economic variables.

\subsection{Testing the Issue Hypothesis}

To test the issue hypothesis we estimate

$$
\begin{aligned}
L_{t}= & \beta_{0}\left(\text { dem } u_{t}-(1-\text { dem })\right) u_{t}+\beta_{1}\left(\operatorname{dem} p_{t}-(1-\text { dem }) p_{t}\right) \\
& +\beta_{2} W A T+\beta_{3} \text { EIS }+\beta_{4} N I X+\beta_{2} R E A .
\end{aligned}
$$

The second column of Table 1 reports the estimation results. The estimates provide strong support to the issue hypothesis. All coefficients have the expected sign and are highly significant. Our findings suggest that Democrats benefit from rising unemployment and Republicans from rising inflation, regardless the political colour of the incumbent President.

TABLE 1 - WEIGHTED LEAST SQUARE ESTIMATES OF POPULARITY FUNCTIONS FOR THE UNITED STATES FOR 1955-1986 (DEPENDENT VARIABLE IS $L_{t}$ )

\begin{tabular}{lrrrr}
\hline & \multicolumn{2}{c}{ Score hypothesis } & \multicolumn{1}{c}{ Issue hypothesis } \\
\hline$p_{t}$ & -0.117 & $(-3.108)$ & & \\
$\left(\right.$ dem $_{t} p_{t}-\left(1-\right.$ dem $\left._{t}\right) p_{t}$ & & & -0.171 & $(-7.780)$ \\
$u_{t}$ & 0.126 & $(3.606)$ & & \\
dem $_{t} u_{t}-\left(1-\right.$ dem $\left._{t}\right) u_{t}$ & & & 0.192 & $(9.460)$ \\
$W A T$ & -0.336 & $(-0.931)$ & $-0.976 \quad(-4.660)$ \\
$E I S$ & 0.279 & $(1.381)$ & 1.184 & $(10.079)$ \\
$N I X$ & 0.105 & $(0.493)$ & 0.293 & $(2.360)$ \\
$R E A$ & -0.362 & $(-1.097)$ & 1.400 & $(7.294)$ \\
$R^{2}$ & 0.413 & & 0.802 & \\
$D W$ & 1.492 & & 1.686 & \\
\hline
\end{tabular}

The figures in parentheses are $t$-values. 
Our finding that high unemployment helps the Democrats and hurts the Republicans has also been found by Meltzer and Vellrath (1975). Unfortunately, they do not relate this outcome to voters' expectations regarding party performance. In their article Meltzer and Vellrath conclude:

'As in sample surveys, we find that the influence of variables shifts, presumably with the importance voters assign to a particular issue. The performance of the economy was, by our criteria, no worse in 1960 than in 1972. Inflation was much higher - 4.1 compared to 1.2 - and average unemployment about the same in 1972 and 1960. Yet the same Republican candidate can be described as having lost the earlier election and won the later election on the issues of prosperity and inflation.'

Now we are able to understand these - at first glance counterintuitive - election outcomes. The issue hypothesis, supported by the data, tells us that the Republican candidate did not win the elections of 1972 in spite of inflation, but rather thanks to inflation.

Comparing the estimates of the popularity function specified according to the score hypothesis and our hypothesis turns out doubtlessly in favour of our hypothesis.

Our study raises the question of to what extent our findings are specific to the US. For The Netherlands a similar hypothesis to the issue hypothesis was rejected by Peeperkorn and Steenkamp (1986), who studied the popularity of Dutch coalitions. In contrast to this study, Swank (1989) found empirical support for the issue hypothesis in explaining the popularity of Dutch political parties. An explanation for these conflicting results might be that coalitions differ less with respect to ideology than political parties. Future research must tell us whether the issue hypothesis is also valid for other countries.

In the theoretical part of this paper, we have disregarded the differences between vote and popularity functions. There are, however, some differences between these functions which might be of importance for the interpretation of the empirical results. Elections are preceded by campaigns, informing (or misinforming) voters on a lot of issues. On the other hand, when opinion polls are taken, voters are considered to react within a few minutes. Another important difference between vote and popularity functions is the meaning of the responses. Election outcomes provide more information than approval rates. If voter $i$ elects for President $j$, this tells us that voter $i$ expects that his utility will be optimal if President $j$ will win the election. This implicity provides information about President $j$ 's opponent. On the other hand, if the same voter approves the stance of President $j$, this does not tell us anything about the expected performance of other candidates. The voter might still prefer candidate $i$, though he approves the stance of President $j$.

According to the issue hypothesis on voting behaviour, voters compare political parties in determining their vote. This hypothesis connects closer to the ex- 
planation of vote functions than to the explanation of popularity functions. Hence we expect that we are also able to explain vote functions with the new hypothesis. Apart from the differences between vote and popularity functions mentioned above, it is generally accepted that vote and popularity functions are closely related to each other (Paldam, 1981).

\section{SOME IMPLICATIONS OF ACCEPTING THE ISSUE HYPOTHESIS FOR STUDIES ON GOVERNMENT BEHAVIOUR}

The results obtained in the previous section induce future research in two fields particularly: first, research into the implications of our findings for studies on government behaviour which use popularity or vote functions, second, research into the factors determining the reputation of political parties. It is far beyond the scope of the present article to discuss both these areas of research extensively. Therefore we confine ourselves to mentioning some promising directions for further research.

The basic idea underlying the issue hypothesis that approval rates depend on the economic problems which a country faces is that voters believe that different parties perform better on different issues. This concept is obviously related to the reputation of political parties with regard to economic policy. In estimating popularity functions for the United States, we have implicitly assumed that the reputation of a political party is fairly constant over time. The question arises of whether this assumption is plausible.

The reputation of a political party concerns the extent to which that party seems to pursue the ideological goals its core constituency desires. Hence reputation is closely related to the ideology of a party. As we have discussed in section 3 , the ideology of a political party can be represented by preference schemes. It seems rather unrealistic to assume voters to know such preference schemes exactly. Small changes in the preference scheme of a party may not change the reputation of that party. Voters, probably, do not even notice small changes in ideology. On the other hand, the probability of sudden large changes in ideology seems negligible, at least in most Western democracies where political parties and social classes are closely related to each other. The core constituency of parties can be expected to exert pressure when the politicians strongly deviate from traditional paths, if such deviations harm the interests of the core constituency.

In the preceding sections we have found that political parties must act in contrast to their ideology if they want to increase their chances of reelection. In other words, they must stake reputation. Policy makers may aim to be reelected for generally two reasons. Of course policy makers may aim to stay in power for individual satisfaction, but even if policy makers pursue ideological goals reelection is important, as it facilitates policy makers achieving their goals. Policy makers are reluctant to risk their reputation. A decline of reputation of a party may decrease the loyalty of its supporters or may even split a party. 
Hence if the popularity of the incumbent party is high it can be expected to pursue its ideology goals. However, the lower the popularity the more an administration is inclined to behave in contrast to its ideology.

From the above it is clear that the policy problem is a rather complicated one. An incumbent party not only faces trade-offs between economic variables, but it is additionally confronted with trade-offs between ideological goals and a reelection goal. These trade-offs raise a dynamic problem since, in trying to increase popularity, policy makers must act in contrast to their ideology, which reduces their reliability or reputation.

\section{CONCLUDING REMARKS}

In this article we have reported estimates of the popularity of US presidents. We have tested two hypotheses: first, the conventional score hypothesis that voters reward and punish administrations for good or bad performance and, second, the issue hypothesis that voters base their decisions on the problems a country faces. Empirical evidence turns out to be strongly in favour of the issue hypothesis. Further research will have to show the validity of the issue model for other countries.

\section{REFERENCES}

Beck, N., 'Parties, Administrations, and American Macroeconomic Outcomes,' American Political Science Review, LXXVI (1982), pp. 82-93.

Borooah, V.K. and F. van der Ploeg, 'The Changing Criteria of Economic Success: Performance and Popularity in British Politics,' Manchester School of Economic and Social Studies, LIX (1982), pp. 61-78.

Chappell, H.W., 'Presidential Popularity and Macroeconomic Performance: Are Voters Really so Naive,' Review of Economics and Statistics, LXV (1983), pp. 385-392.

Edwards, G.C. III, The Public Presidency, New York, 1983.

Fair, R.C., 'The Effect of Economic Events on Votes for President,' Review of Economics and Statistics, LX (1978), pp. 159-173.

Frey, B.S. and F. Schneider, 'A Politico-economic Model of the United Kingdom,' Economic Journal, LXXVIII (1978a), pp. 243-253.

Frey, B.S. and F. Schneider, 'An Empirical Study of Politico-Economic Interaction in the United States,' Review of Economics and Statistics, LX (1978b), pp. 172-183.

Goodhart, C.A.E. and R.J. Bhansali, 'Political Economy,'Political Studies, XVIII (1971), pp. 43-106.

Hanushek, E.A. and J.E. Jackson, Statistical Methods for Social Scientists, London, 1977.

Hibbs, D., 'Political Parties and Macro-economic Policy,' American Political Science Review, LXXI (1977), pp. 1467-1487.

Hibbs, D.A., 'On the Demand for Economic Outcomes: Macroeconomic Performance and Mass Political Support in the United States, Great Britain and Germany,'Journal of Politics, XLIV (1982), pp. 426-461. 
Hibbs, D.A. Jr., 'Political Parties and Macroeconomic Policies and Outcomes in the United States,' American Economic Review, LXXVI (1986), pp. 66-70.

Kramer, G.H., 'Short-term Fluctuations in U.S. Voting Behaviour, 1986-1964,' American Political Science Review, LXV (1971), pp. 131-143.

MacRae, C.D., 'A Political Model of the Business Cycle,' Journal of Political Economy, LXXXV (1981), pp. 239-263.

MacRae, D.C., 'On the Political Business Cycle,' in: D.A. Hibbs and H. Fassbender (eds.), Contempory Political Economy, Amsterdam, 1981.

Meltzer, A.N. and M. Vellrath, 'The Effects of Economic Policies on Votes for the Presidency: Some Evidence from Recent Elections,' Journal of Law and Economics, XVIII (1975), pp. 781-798.

Mosley, P., The Making of Economic Policy, Brighthon, 1984.

Mueller, J., 'Presidential Popularity from Truman to Johnson,' American Political Science Review, LXIV (1970), pp. 18-34.

Paldam, M. 'A Preliminary Survey of the Theories and Findings of Vote and Popularity Functions,' European Journal of Political Research, IX (1981), pp. 181-199.

Peeperkorn, L.P.M. and T.B.M. Steenkamp, 'Regeringspopulariteit en economische omstandigheden,' Maandschrift Economie, L (1986), pp. 85-98.

Renaud, P.S.A. and F.A.A.M. van Winden, 'On the Importance of Elections and Ideology for Government Policy in a Multi-party System,' in: M.J. Holler (ed.), The Logic of Multiparty Systems, Dordrecht, 1987.

Swank, O.H., 'De invloed van economische variabelen op verkiezingen,' Economisch Statistische Berichten, LXXIV (1989), pp. 820-823.

Theil, H., Economic Forecasts and Policy, Amsterdam, 1958.

Winden, F.A.A.M. van, On the Interaction Between State and Private Sector, Amsterdam, 1983.

\section{Summary}

\section{PRESIDENTIAL POPULARITY AND REPUTATION}

This paper reports on the results of an empirical study of relationships between the popularity of US presidents and economic variables. Traditionally, these relationships are based on the hypothesis that voters hold the incumbent President responsible for the economic situation. We derive an alternative specification of popularity, based on the hypothesis that political parties perform better on different issues. Empirical evidence turns out to be strongly in favour of our hypothesis. Our findings have important implications for studies on government behaviour in which it is assumed that one of the objectives of administrations is to maximise votes. 